\title{
Rapid uptake of oxidized ascorbate induces loss of cellular glutathione and oxidative stress in liver slices
}

\author{
Jin Hyang Song ${ }^{1}$, Chantelle Simons ${ }^{1}$, \\ Lily Cao ${ }^{1}$, Seon Ho Shin ${ }^{1}$, \\ Murray Hong ${ }^{1}$ and III Min Chung ${ }^{2,3}$ \\ ${ }^{1}$ Department of Physiology, Queen's University \\ Kingston, Ontario, Canada K7L 3N6 \\ ${ }^{2}$ College of Life and Environment Science \\ Konkuk University, Seoul 143-701, Korea \\ ${ }^{3}$ Corresponding author: Tel, 82-2-450-3730; \\ Fax, 82-2-446-7856; E-mail, imcim@kkucc.konkuk.ac.kr
}

Accepted 24 February 2003

Abbreviations: GLUT, glucose transporter; TBARS, thiobarbituric acid-reactive substances; WT, wortmannin

\begin{abstract}
The observation that ascorbate known to retain prooxidant properties induces cell death in a number of immortal cell lines, led us to examine its mechanism and whether it is involved in oxidative stress injury in such asocorbate-enriched tissue cells as hepatocytes. In rat liver homogenates, higher concentrations ( 1 and $3 \mathrm{mM}$ ) of ascorbate suppressed lipid peroxide productions but lower concentrations $(0.1$ and $0.3 \mathrm{mM})$ did not. In contrast to the homogenate, ascorbate increased lipid peroxide production in liver slices in a concentration dependant manner. Iso-ascorbate, the epimer of ascorbate did not cause an increase the oxidative stress in liver slices. This differential effect between homogenates and liver slices implies that cellular integrity is required for ascorbate to induce oxidative stress. Wortmannin, an inhibitor of the GLUT (glucose transporter) thought to transport dehydroascorbate into cells, inhibited $\left[{ }^{14} \mathrm{C}\right]$ ascorbate uptake and suppressed oxidative stress in liver slices. Wortmannin suppressed that $\left[{ }^{14} \mathrm{C}\right]-$ ascorbate uptake by GLUT following oxidation to $\left[{ }^{14} \mathrm{C}\right]$ dehydroascorbate. Taken together, these observations support our hypothesis that ascorbate is oxidized to dehydroascorbate by molecular oxygen in solution (i.e., plasma and culture medium) which is then carried into hepatocytes (via a GLUT) where it is reduced back to ascorbate causing oxidative stress.
\end{abstract}

Keywords: ascorbic acid; dehydroascorbic acid; glucose transporter; glutathione; lipid peroxide

\section{Introduction}

Ascorbate acts as a scavenger of reactive oxygen species, including superoxide and hydroxyl free radicals, which are produced by radiation, oxidative reactions and carcinogenic processes (Ozaki et al., 1995). As such the ascorbate anion donate an electron to the free radicals. Ascorbate is also required to maintain the structural integrity of vascular tissues and plays vital roles in a number of other physiological processes, including platelet function, and cholesterol and catecholamine biosynthesis (Agus et al., 1997). With all of these well-established positive attributes it may come as a surprise to some that, in reality, ascorbate is somewhat of a paradoxical molecule. Contrary to the antioxidant properties of ascorbate, it has also been shown to oxidize cellular components under certain experimental conditions (Roginsky and Stegmann, 1994; Pushpendran et al., 1998) and to induce cell death in a number of different cell lines (Sakagami and Satoh, 1997), even though the mechanism is not well understood.

The liver is susceptible to a wide variety of disorders, possibly because it is constantly exposed to so many harmful agents. Liver damage induced by ischemia-reperfusion is generally recognized as being mediated by oxidative stress (Layton et al., 1996; Cerwenka et al., 1999) but considerable uncertainty surrounds the mechanism of oxidative stress-induced damage. The liver is also considered to be a reservoir: maintaining homeostatic level of plasma ascorbate since it stores a large amount of ascorbate (Hornig, 1975; Upston et al., 1999). The physiological significance of high concentration of ascorbate in liver is, however, not well defined.

We hypothesized that the pro-oxidant action of ascorbate may be involved in the liver damage that follows ischemia. This proposition is based on the observation that ascorbate concentrations are increased by $60 \%$ in liver extracellular fluid during ischemia (Layton et al., 1996). This indicates that physiological concentrations of ascorbate within hepatocytes (approximately $4.3 \pm 0.5 \mathrm{mM}$ ) cannot be maintained during an ischemic period (Rose and Bode, 1995). The released ascorbate in plasma is oxidized by molecular oxygen ( $\mathrm{Pa}_{2}$ 95 \pm 2 torr) (Walker et al., 1997). During 
the reperfusion period, hepatocytes actively take up ascorbate to restore physiological concentrations of the vitamin. A major source of ascorbate reuptake takes the form of dehydroascorbate (DHA) transport via a glucose transporter (GLUT) (Banhegyi et al., 1998). The cytosolic dehydroascorbate is rapidly reduced to ascorbate by the action of dehdroascorbate reductase and a non-enzymatic chemical reaction. However, rapid rises in hepatocyte dehydroascorbate concentrations decrease the ability of cellular reducing agents such as glutathione (GSH) to reduce further oxidative stress, and eventually result in liver injury through deregulation of vital cellular components.

In this study, we obtained evidence supporting our putative mechanism that a rapid uptake rate of dehydroascorbate (oxidized ascorbate) is a critical factor in the development of liver injury during the reperfusion period.

\section{Materials and Methods}

Male Sprague-Dawley rats were obtained from Charles River Canada (Montreal, Canada). The rats were acclimatized at $25^{\circ} \mathrm{C}$ for two weeks with $14 \mathrm{~h}(06$ : 00-20:00) of light daily. Their diets consisted of Purina Lab Chow and tap water supplied ad libitum. All of the following experimental protocols were carried out in accordance with guidelines established by the Queen's University Animal Care Committee.

Rats (280-300 g) were killed by decapitation under halothane anesthesia and their liver lobes removed. Ten percent liver homogenate was prepared by homogenizing $1 \mathrm{~g}$ (wet weight) of liver tissue in $9 \mathrm{ml}$ of PBS $\left(0.15 \mathrm{M} \mathrm{NaCl}\right.$ and $\left.10 \mathrm{mM} \mathrm{Na}_{2} \mathrm{HPO}_{4}, \mathrm{pH} 7.4\right)$ using a frosted glass tube-pestle. The homogenate (1 $\mathrm{ml} /$ tube) was transferred to glass test tubes $(15 \times 75$ $\mathrm{mm}$ ) and the ascorbate (Sigma-Aldrich Canada Ltd., Oakville, ON, Canada) added to make $0.1,0.3,1$, or $3 \mathrm{mM}$. In some cases as noted in the text, $50 \mu \mathrm{M}$ ferrous ions $\left[\mathrm{Fe}^{2+}\right.$, ammonium iron (II) sulfate; Fisher Scientific] were also added to assess the impact of ascorbate plus $\mathrm{Fe}^{2+}$ on lipid peroxidation in liver slices and homogenates. Samples were incubated for three hours in a water bath at $37^{\circ} \mathrm{C}$.

In order to quantify the concentration of oxidized lipids the amount of thiobarbituric acid-reactive substances (TBARS) was determined. Two $\mathrm{ml}$ of $0.67 \%$ thiobarbituric acid (Sigma-Aldrich Canada Ltd.) was added to $100 \mu$ of the homogenate in glass test tubes $(15 \times 75 \mathrm{~mm})$ and placed into a boiling water bath for $20 \mathrm{~min}$. Tubes were cooled on ice and then centrifuged at $3,000 \mathrm{~g}$ for $10 \mathrm{~min}$. A spectrophotometer was used to measure the optical density of the solutions at $532 \mathrm{~nm}$. A standard curve was constructed using tetraethoxy propane (Sigma-Aldrich Ca- nada Ltd.) as a reference $(r=0.99)$, from which the concentrations of TBARS are determined. TBARS concentrations of control group were expressed as $100 \%$ to facilitate comparisons among ascorbate concentrations in different samples.

To determine the effect of ascorbate treatment on liver slices, rat livers were placed in RPMI 1640 (Gibco, Grand Island, New York) containing 2.5\% fetal bovine serum, 10\% horse serum (Gibco) and $50 \mathrm{lU} / \mathrm{ml}$ penicillin (Sigma-Aldrich Canada Ltd.) (culture medium). Liver samples were sliced to less than $1 \mathrm{~mm}$ using a razor blade. The liver tissue $(0.4 \mathrm{~g})$ was placed in Teflon beakers containing $3.6 \mathrm{ml}$ of culture medium. Ascorbate was added to make concentrations of $0.1,0.3,1$ or $3 \mathrm{mM}$, respectively. Samples were incubated in a water-jacketed incubator at $37^{\circ} \mathrm{C}$ under a water-saturated atmosphere of $5 \% \quad \mathrm{CO}_{2}-95 \%$ air for $2 \mathrm{~h}$. Following the incubation period, both the tissue and medium were transferred to a $15 \mathrm{ml} \mathrm{screw-}$ cap conical centrifuge tube and centrifuged for $3 \mathrm{~min}$ at $1,000 \mathrm{~g}$. The media was discarded while the pellet was resuspended in $1 \mathrm{ml}$ of PBS solution. The suspension was recentrifuged at $1,000 \mathrm{~g}$ for $3 \mathrm{~min}$. A $10 \%$ homogenate was prepared and the concentrations of oxidized lipids (TBARS) quantified as described above.

The Lowry protein assay was employed to quantify protein contents in each aliquot sample of homogenate (Lowry et al., 1951). Thus, TBARS levels were expressed as nmol per $100 \mathrm{mg}$ of protein to standardize the amounts of oxidized lipids among tissue samples.

Some of the experiments were aimed at determining the effect of wortmannin (Sigma-Aldrich Canada Ltd.) or GSH on the attenuation of lipid peroxidation induced by ascorbate. In these experiments, wortmannin or glutathione was added for a final concentration of $10 \mu \mathrm{M}$ or $1 \mathrm{mM}$ respectively. The tissue concentrations of reduced glutathione were measured according to the method of Hissin and Hilf (1976) with minor modifications. Liver homogenates $(250 \mathrm{mg})$ were centrifuged and pellets washed with $0.5 \mathrm{ml}$ of $25 \% \mathrm{Na}_{2} \mathrm{HPO}_{3}$ and $2 \mathrm{ml}$ of $0.1 \mathrm{M}$ sodium phosphate- 5 mM EDTA buffer ( $\mathrm{pH} 8.0$ ) by resuspension and recentrifugation. After centrifugation at $10,000 \mathrm{~g}$ for 30 min, aliquots of the supernatant $(0.5 \mathrm{ml})$ were mixed with $4.5 \mathrm{ml}$ of phosphate-EDTA buffer. Also, $100 \mu \mathrm{l}$ of O-phthalaldehyde and $1.8 \mathrm{ml}$ of phosphate-EDTA buffer were added to a $100 \mu \mathrm{l}$ test sample. The solution was mixed, and incubated at room temperature for $15 \mathrm{~min}$. The contents of glutathione were determined fluorometrically with excitation and emission at $350 \mathrm{~nm}$ and $420 \mathrm{~nm}$, respectively. Data were calculated on the basis of glutathione calibration curves.

In order to investigate the effect of GLUT inhibitors on dehydroascorbate transportation (Agus et al., 1997; 
Song et al., 2002), liver slices were incubated with $1 \mathrm{ml}$ of $10 \mu \mathrm{M}$ ascorbate containing $0.1 \mu \mathrm{Ci}\left[{ }^{14} \mathrm{C}\right]-$ ascorbate $(8.60 \mathrm{mCi}$ per $\mathrm{mmol}$, Dupont Canada Inc., Mississauga, ON, Canada) in the presence or absence of 1 or $10 \mu \mathrm{M}$ wortmannin for $4 \mathrm{~h}$ in a shaking water bath at $37^{\circ} \mathrm{C}$. To collect slices, incubation samples were centrifuged at $1,000 \mathrm{~g}$ and washed twice with $2 \mathrm{ml}$ PBS $(\mathrm{pH} 7.4)$ to remove surface $\left[{ }^{14} \mathrm{C}\right]$ ascorbate. The liver slices were homogenized in $100 \mu \mathrm{l}$ PBS and transferred to $4 \mathrm{ml}$ of Scintiverse (Fisher Scientific Canada, Nepean, ON, Canada). Total radioactivity in the samples was determined by liquid scintillation counting (Beckman).

The Graph-Pad Prism (GraphPad, San Diego, CA) was used for all statistical analysis. The one-way ANOVA with Bonferroni $t$ post-test and Student's $t$-test were used to assess differences among groups. Data are presented as the mean \pm SE; $P$ values of less than 0.05 were determined to be significant.

\section{Results}

In liver slices, ascorbate treatments elevated TBARS concentration in a dose-related manner over a range of concentration between 0 (control) and $3 \mathrm{mM}$ ascorbate (upper panel, Figure 1) $(r=0.910 \pm 0.048, n=6)$. Treatment with 1 and $3 \mathrm{mM}$ ascorbate significantly elevated the TBARS concentrations in liver slices to $152 \pm 6 \% \quad(P<0.05)$ and $168 \pm 14 \% \quad(P<0.01)$ but not by treatments of lower concentrations $(0.1$ and 0.3 $\mathrm{mM})$. Conversely, in liver homogenates TBARS concentrations were elevated by treatment with lower concentrations of ascorbate $(0.1$ and $0.3 \mathrm{mM})$ to 135 $\pm 10 \%$ and $155 \pm 14 \% \quad(P<0.05)$, respectively but higher ascorbate concentrations ( 1 and $3 \mathrm{mM}$ ) failed to elevate TBARS concentration forming a bell shaped concentration-response curve (lower panel, Figure 1).

When the liver slices were treated with $50 \mu \mathrm{M} \mathrm{Fe}{ }^{2+}$ in addition to varying concentrations $(0,0.1,1$ and $3 \mathrm{mM}$ ) of ascorbate (upper panel, Figure 2), treatment with $50 \mu \mathrm{M} \mathrm{Fe}^{2+}$ alone [control group $(0 \mathrm{mM}$ ascorbate) in upper panel, Figure 2] did not increase the TBARS concentration $(94 \pm 6 \%)$ when compared to the control group $(100 \pm 5 \%)$. High concentrations of ascorbate $(1$ and $3 \mathrm{mM})$ in the presence of $50 \mu \mathrm{M}$ $\mathrm{Fe}^{2+}$ significantly elevated the TBARS concentrations to $152 \pm 16 \% \quad(P<0.05)$ and $168 \pm 20 \% \quad(P<0.01$, $n=6$ ) (upper panel, Figure 2). However, ascorbatetreated groups without (upper panel, Figure 1) and with $50 \mu \mathrm{M} \mathrm{Fe}^{2+}$ (upper panel, Figure 2) did not differ, indicating that $50 \mu \mathrm{M} \mathrm{Fe}{ }^{2+}$ did not contribute to TBARS production in the liver slices.

Liver homogenates were treated with different concentrations $(0,0.1,0.3,1$ and $3 \mathrm{mM})$ of ascorbate
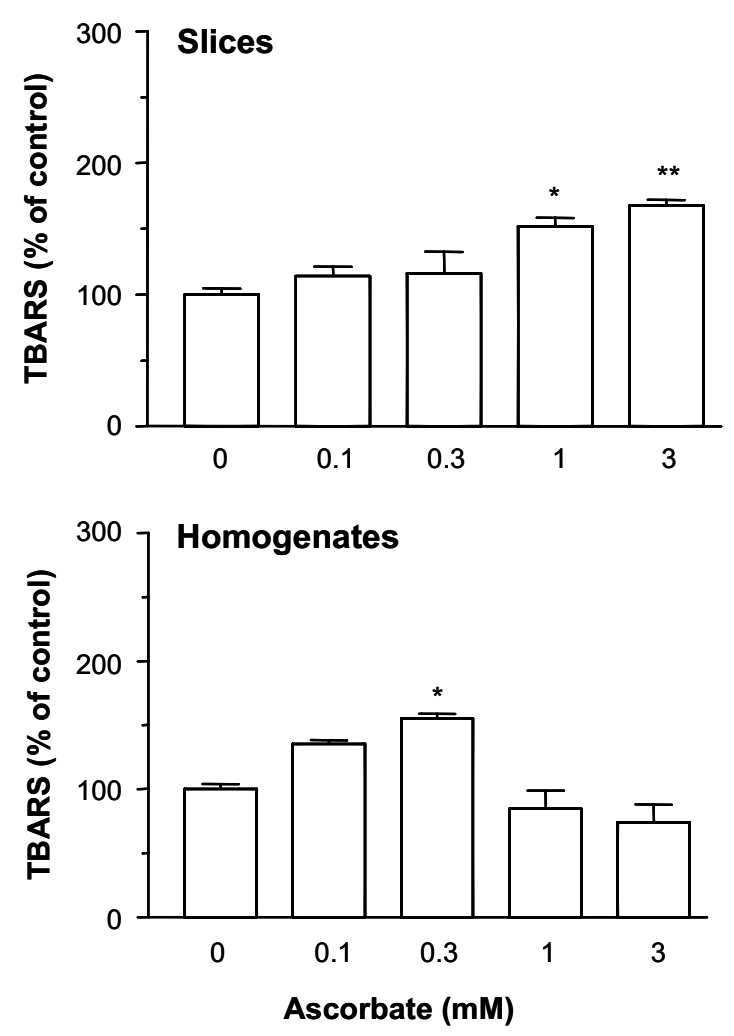

Figure 1. Effects of ascorbate treatment on liver slices (upper panel) and liver tissue homogenates (lower panel). Quantities of TBARS are expressed as percentages of control values. Each bar represents the mean \pm SEM of six replicates. ${ }^{*} P<0.05,{ }^{*} P<0.01$.

in the presence of $50 \mu \mathrm{M} \mathrm{Fe}{ }^{2+}$. While $\mathrm{Fe}^{2+}$ alone did not significantly $(P=0.1041)$ increase TBARS mean values above control values (TBARS concentrations with $\mathrm{Fe}^{2+}$ were $119 \pm 4 \%$, and control values were 100 $\pm 4 \%), 0.1$ and $0.3 \mathrm{mM}$ ascorbate plus $50 \mu \mathrm{M} \mathrm{Fe}{ }^{2+}$ elevated TBARS concentrations to $214 \pm 15 \%(P<$ $0.01, n=6)$ and $225 \pm 28 \%(P<0.01, n=6)$, respectively. However, higher concentration of ascorbate (1 and $3 \mathrm{mM}$ plus $50 \mu \mathrm{M} \mathrm{Fe}{ }^{2+}$ ) did not increase TBARS concentrations above control values (lower panel, Figure 2). The ascorbate plus $50 \mu \mathrm{M} \mathrm{Fe}{ }^{2+}$ group also showed a bell shaped dose-response curve but the magnitude of elevation of TBARS was higher in 0.1 $\mathrm{mM}(P<0.01)$ and $0.3 \mathrm{mM}$ ascorbate-treated groups $(P<0.001)$ (lower panel, Figure 2$)$ than those ascorbate-treated groups without $\mathrm{Fe}^{2+}$ (lower panel, Figure 1). Thus, $50 \mu \mathrm{M} \mathrm{Fe}{ }^{2+}$ potentiated ascorbateinduced oxidative stress in the homogenates.

Trace amounts of metal ions such as ferrous ion are found in chemical reagents as impurities and may influence ascorbate-induced oxidative stress. EDTA $(10,30,100$ and $300 \mu \mathrm{M})$ was added to the culture media to eliminate the effects of trace metal ions. When the homogenates were treated with $0.1 \mathrm{mM}$ 

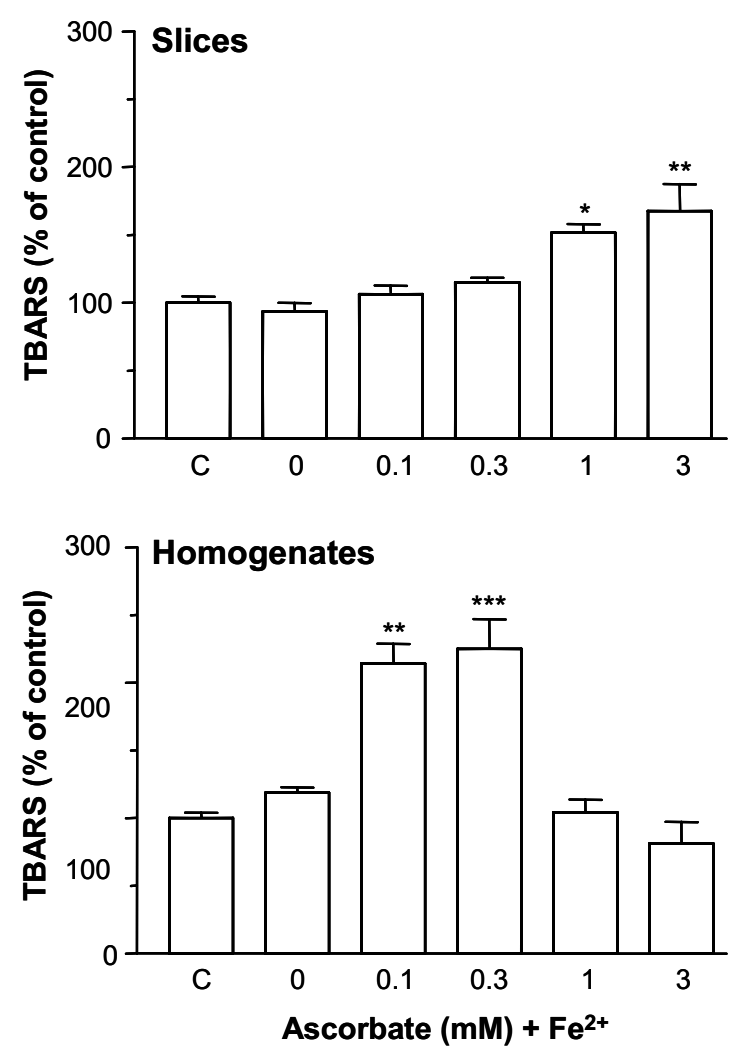

Figure 2. Effect of ascorbate treatment on liver slices (upper panel) and liver tissue homogenates (lower panel) in the presence of $50 \mu \mathrm{M}$ ferrous ion $\left(\mathrm{Fe}^{2+}\right)$. C, absolute control without ascorbate and $\mathrm{Fe}^{2+}$. Quantities of TBARS are expressed as percentages of control values. Each bar represents the mean \pm SEM of six replicates. ${ }^{*} P<0.05$, ${ }^{* *} P<0.01,{ }^{* * *} P<0.001$.

ascorbate plus $50 \mu \mathrm{M} \mathrm{Fe}{ }^{2+}$, TBARS concentrations were elevated to $248 \pm 20 \%$ above control and increasing concentrations of EDTA $(0,30,100,300 \mu \mathrm{M})$ lowered TBARS concentrations in a concentration dependent manner (lower panel, Figure 3, $r=0.739$ ). These observations showed that $300 \mu \mathrm{M}$ EDTA was sufficient to inactivate $50 \mu \mathrm{M} \mathrm{Fe}{ }^{2+}$, and thus trace amounts of contaminating transition metal ions should be completely removed by treatment with EDTA.

In liver slices with both $50 \mu \mathrm{M} \mathrm{Fe} \mathrm{F}^{2+}$ and $1 \mathrm{mM}$ ascorbate, TBARS concentration were increased to $153 \pm 10 \%$ (upper panel, Figure 3), confirming previous experiments on liver slices (upper panel, Figure 2). However, when different concentrations of EDTA $(0,10,30,100,300 \mathrm{mM})$ were added to the medium containing $1 \mathrm{mM}$ ascorbate and $50 \mu \mathrm{M} \mathrm{Fe}{ }^{2+}$, EDTA did not alter TBARS concentrations (upper panel, Figure 3) confirming that ferrous ions did not contribute to generating oxidative stress in liver slices.

We next examined whether iso-ascorbate, an epimer of ascorbate induces oxidative stress. The primary chemical structure of iso-ascorbate is the same
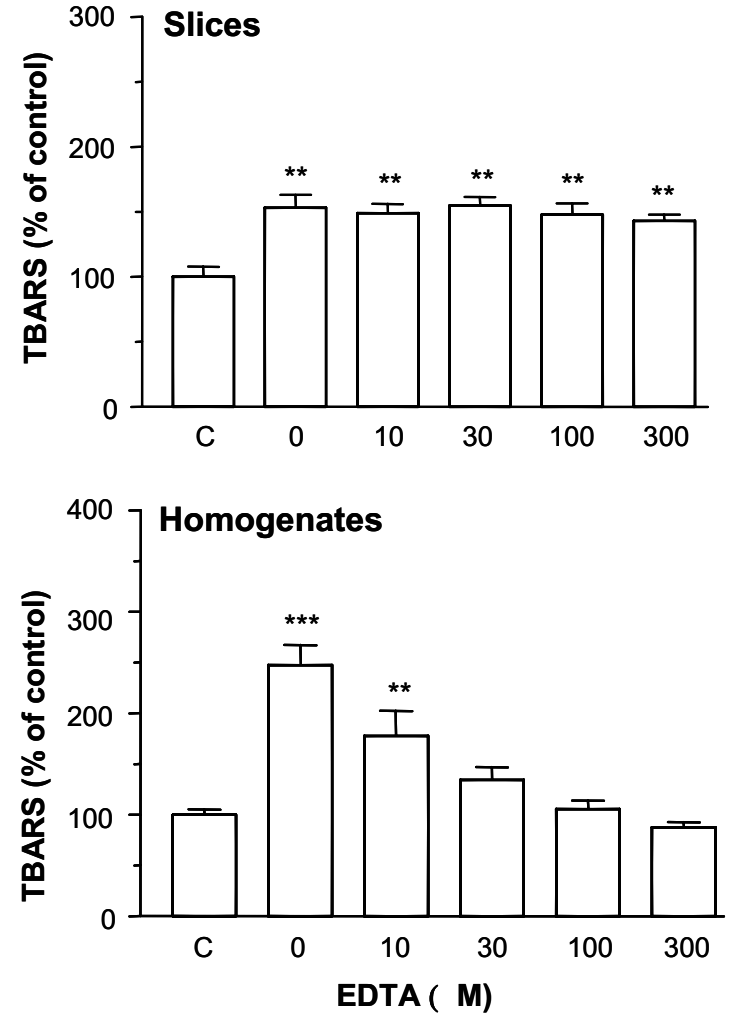

Figure 3. Effects of EDTA treatment on liver slices (upper panel) in the presence of $0.1 \mathrm{mM}$ ascorbate plus $50 \mu \mathrm{M}$ ferrous ion $\left(\mathrm{Fe}^{2+}\right)$, and liver tissue homogenates (lower panel) in the presence of $0.1 \mathrm{mM}$ ascorbate plus $50 \mu \mathrm{M} \mathrm{Fe}^{2+}$. C, absolute control without ascorbate, $\mathrm{Fe}^{2+}$ and EDTA. Quantities of TBARS were expressed as percentages of control values. Each bar represents the mean \pm SEM of six replicates. ${ }^{* *} P<0.01,{ }^{* * *} P<0.001$.

as ascorbate. In contrast to the oxidative action of ascorbate in liver slices, iso-ascorbate concentrations up to $3 \mathrm{mM}$ did not elevate TBARS productions above control values (Figure 4).

Ascorbate is easily oxidized to dehydroascorbate, and it is known that cells take up dehydroascorbate from extracellular fluid through a GLUT (Banhegyi et al., 1998), and that GLUT inhibitors such as wortmannin suppress the transport capacity of glucose. We measured the uptake of $\left[{ }^{14} \mathrm{C}\right]$ ascorbate in liver slices. Treatment groups containing 1 or $10 \mu \mathrm{M}$ wortmannin showed significantly lower quantities of radioactivity $(76 \pm 8 \%, P<0.05$ or $62 \pm 5 \%, P<0.01)$ than the control group $(100 \pm 5 \%)$ in hepatocytes after $4 \mathrm{~h}$ incubations. These observations support the concept that $\left[{ }^{14} \mathrm{C}\right]$ ascorbate is taken up through a GLUT after oxidation to $\left[{ }^{14} \mathrm{C}\right]$ dehydroascorbate as wortmannin suppressed uptake of the labeled compound (Figure 5).

In order to further elucidate the mechanism of oxidative stress induced by ascorbate, the effects of glutathione and wortmannin on TBARS production 


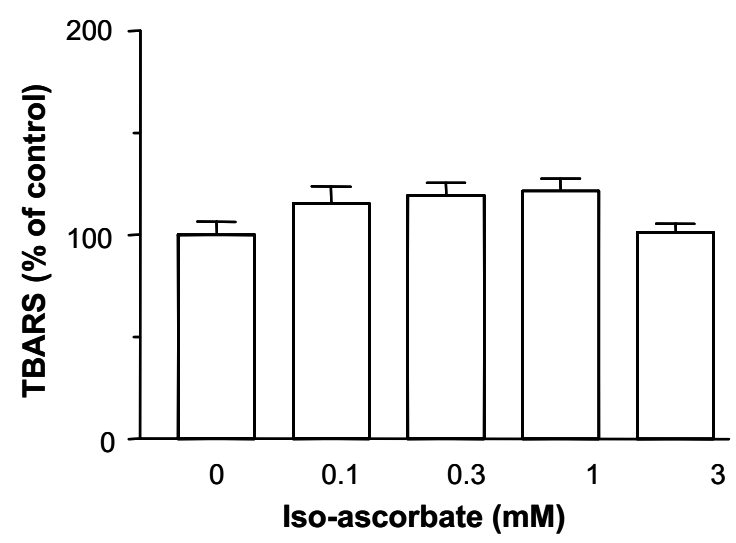

Figure 4. Effects of iso-ascorbate treatment on liver slices. Quantities of TBARS were expressed as percentages of control values. Each bar represents the mean $\pm S E M$ of six replicates. No significant differences were found. Each bar represents the mean \pm SEM of six replicates.

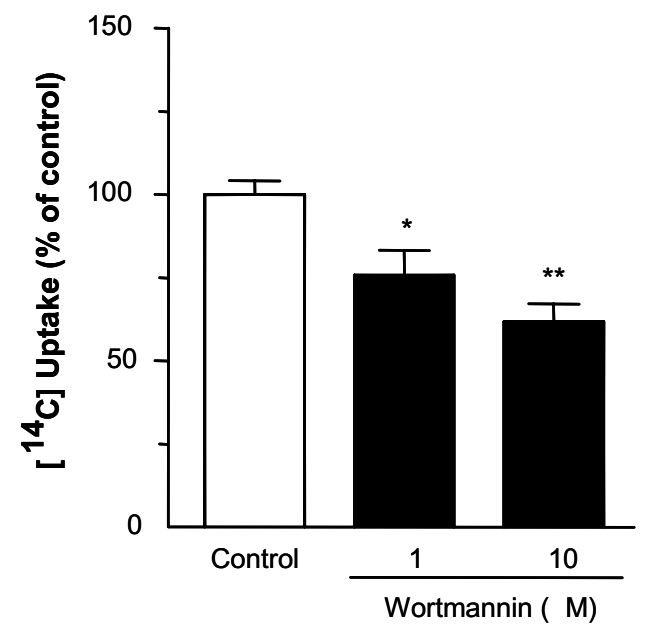

Figure 5. Effects of wortmannin on uptake of ${ }^{14} \mathrm{C}$-labeled compound. Liver slices were treated with either $1 \mu \mathrm{M}$ or $10 \mu \mathrm{M}$ wortmannin in culture medium containing $0.1 \mu \mathrm{Ci}\left[{ }^{14} \mathrm{C}\right]$ ascorbate plus $10 \mu \mathrm{M}$ ascorbate. DPM of ${ }^{14} \mathrm{C}$-labeled compound were counted, converted to DPM/mg protein and expressed as percentages of control values. Each bar represents the mean \pm SEM of six replicates. ${ }^{*} P<0.05$, ${ }^{* *} P<0.01$.

were tested. While $1 \mathrm{mM}$ glutathione or $10 \mu \mathrm{M}$ wortmannin alone did not change TBARS concentration (control group, Figure 6), we again confirmed that 1 and $3 \mathrm{mM}$ ascorbate stimulated TBARS productions to $162 \pm 6 \%$ and $167 \pm 14 \%$, respectively (Figure 6 ). The 1 or $3 \mathrm{mM}$ ascorbate-induced TBARS production in the presence of $1 \mathrm{mM}$ glutathione were suppressed from $162 \pm 6 \%$ to $109 \pm 24 \%(P<0.05)$ or from 168 $\pm 14 \%$ to $104 \pm 10 \%(P<0.001)$, respectively (Figure $6, n=6)$. Thus, $1 \mathrm{mM}$ glutathione prevents oxidation of ascorbate to dehydroascorbate. The TBARS concentrations in the presence of $10 \mu \mathrm{M}$ wortmannin and

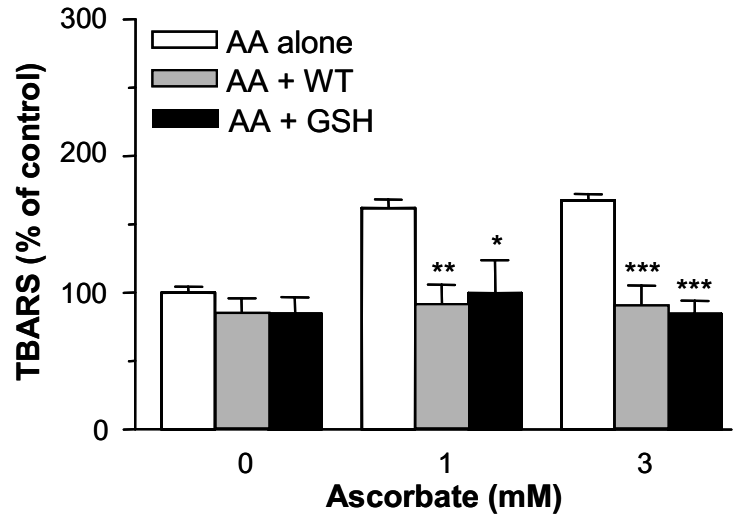

Figure 6. Effects of wortmannin and glutathione on TBARS production induced by ascorbate. Liver slices were treated with different concentrations of ascorbate $(0,1$, and $3 \mathrm{mM})$ in presence of $10 \mu \mathrm{M}$ wortmannin $(A A+W T)$ or $1 \mathrm{mM}$ glutathione $(A A+G S H)$. Each bar represents the mean \pm SEM of six replicates. ${ }^{*} P<0.05$, ${ }^{* *} P<0.01$, ${ }^{* * *} P$ $<0.001$ vs AA alone.

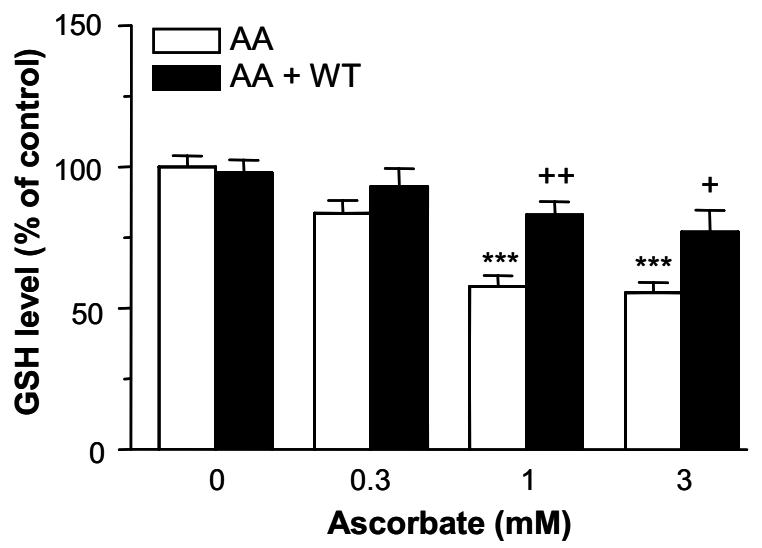

Figure 7. Effects of wortmannin on ascorbate-induced changes of endogenous glutathione (GSH) levels in liver slices. Liver slices were treated with different concentrations of ascorbate $(0,1$, and $3 \mathrm{mM})$ without (AA) or with $10 \mu \mathrm{M}$ wortmannin $(\mathrm{AA}+\mathrm{WT})$. Each bar represents the mean $\pm S E M$ of six replicates. ${ }^{* * *} P<0.001$; difference between control and treatment group. ${ }^{+} P<0.05,{ }^{++} P<0.01$; difference between treatment groups of ascorbate and ascorbate plus wortmannin.

$1 \mathrm{mM}(109 \pm 17, P<0.01)$ or $3 \mathrm{mM}$ ascorbate (101 $\pm 14 \%, P<0.01$ ) were significantly lower than those of $1 \mathrm{mM}(162 \pm 6 \%, P<0.01)$ or $3 \mathrm{mM}(167 \pm 14 \%$, $P<0.001$ ) ascorbate alone (Figure 6), supporting our hypothesis that wortmannin inhibits the "dehydroascorbate transporter" (GLUT).

In order to further support the notion that ascorbate generates oxidative stress, endogenous glutathione concentrations in the liver slices were determined. Endogenous glutathione concentrations in liver slices were significantly reduced in a concentration-dependent manner after ascorbate treatments (Figure 7, 


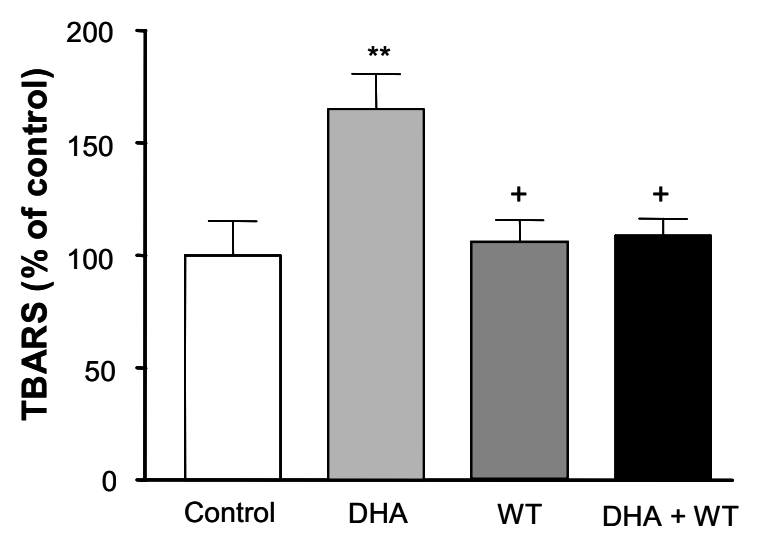

Figure 8. Effect of dehydroascorbate in liver slices. Liver slices were treated with $1 \mathrm{mM}$ dehydroascorbate without (DHA) or with $10 \mu \mathrm{M}$ wortmannin (DHA+Wortmannin). Each bar represents the mean \pm SEM of six replicates. ${ }^{* *} P<0.01$, difference between control and treatment group. ${ }^{+} P<0.05$, difference between treatment groups of DHA and DHA plus wortmannin.

$r=0.806$ ). Higher concentrations of ascorbate (1 and $3 \mathrm{mM}$ ) significantly decreased glutathione levels to 58 $\pm 4 \%(P<0.001)$ and $56 \pm 4 \%(P<0.001)$, respectively. The glutathione concentrations in treatment groups with ascorbate ( 1 and $3 \mathrm{mM}$ ) and $10 \mu \mathrm{M}$ wortmannin were higher than those induced by ascorbate alone (Figure 7), as confirmed by TBARS levels in liver slices. Interestingly, treatment of liver slices with $1 \mathrm{mM}$ dehydroascorbate resulted in a TBARS level that was $165 \pm 16 \%(P<0.01, n=6)$ greater than control values and TBARS levels in liver slices incubated with $1 \mathrm{mM}$ dehydoascorbate in the presence of $10 \mu \mathrm{M}$ wortmannin was significantly lower than that of dehydroascorbate alone $(109 \pm 7 \%, \quad P<0.05)$ (Figure 8), consistent with other observations that high levels of dehydroascorbate have been proven to be toxic to various cells and tissues (Paolicchi et al., 1996; Song et al., 1999 and 2001).

\section{Discussion}

Few mechanisms have been proposed to explain the pro-oxidant action of ascorbate. One of them is the Fenton reaction in which ascorbate reacts with ferrous ion $\left(\mathrm{Fe}^{2+}\right)$ to generate free hydroxyl radicals that have a powerful oxidative potential (Cardoso et al., 1998; Miller and Aust, 1989). This is a logical explanation since a substantial amount of iron is found in hemoglobin and its breakdown products and also since ascorbate is highly concentrated in several tissues such as adrenal glands and liver (Hornig, 1975). We have confirmed that ferrous ions potentiate ascorbateinduced oxidative stress in liver homogenates (lower panels, Figure 1 and 2). In liver slices, however, the level of ascorbate-induced oxidative stress did not further increase when the slices were also treated with ferrous ions (upper panels, Figure 1 and 2). Oxidative stress indicated by TBARS levels in liver slices treated with ascorbate plus $\mathrm{Fe}^{2+}$ contradict other studies that suggest an ascorbate- $\mathrm{Fe}^{2+}$ interaction is responsible for inducing lipid peroxidation (Ramassamy et al., 1994; Cardoso et al., 1998). However, none of the encountered studies examined the impact of ascorbate treatment in culture medium. It is believed that in serum containing medium, iron binds to the proteins and is thus unable to interact with the ascorbate in order to induce oxidative stress. To further confirm that oxidative stress is not due to an interaction between ascorbate and ferrous ions, we examined the extent of lipid peroxidation in culture medium containing ascorbate, $\mathrm{Fe}^{2+}$ and EDTA. EDTA is a powerful metal chelator (Song et al., 1999). Thus, if no significant difference is detected among groups containing EDTA or not, such would further support the proposition that no heavy metal ion significantly influences the extent of lipid peroxidation. In present study, EDTA eliminated ferrous ion-induced oxidative stress in liver homogenates (lower panel, Figure 3), but was ineffective in liver slices in reducing TBARS concentrations generated by both $0.1 \mathrm{mM}$ ascorbate and $50 \mu \mathrm{M}$ ferrous ion (upper panel, Figure 3 ). This result was consistent with our previous observation that the combination of ascorbate $(10-100 \mu \mathrm{M})$ and ferrous ion increased concentrations of TBARS in PC12 cells and cerebrocortical homogenates, but did not increase TBARS when the medium was supplemented with $10 \%$ fetal bovine serum or albumin (Song et al., 2001). Thus, it is unlikely that the Fenton reaction is a mechanism of ascorbate-induced oxidative stress in culture medium containing serum or in in situ tissues where plasma is freely available.

We proposed an alternative mechanism to explain ascorbate-induced oxidative stress. Ascorbate is a powerful reducing agent and thus is easily oxidized to ascorbyl radical and then to dehydroascorbate. Ascorbate is known to be transported into cells via three different mechanisms: (i) $\mathrm{Na}^{+}$dependent uptake (Spector and Lorenzo, 1973), (ii) glutamate-ascorbate heteroexchange (Miele et al., 1994) and (iii) via a GLUT (Vera et al., 1993). The first two mechanisms of ascorbate uptake do not generate any oxidative stress since ascorbate cannot accept additional electrons under normal conditions. GLUT is an efficient transporter for ascorbate uptake in the form of dehydroascorbate (Welch et al., 1995), and the only carrier system which can generate oxidative stress (Song et al., 2001 and Brown et al., 2002). After being taken up into the cytosol, dehydroascorbate is rapidly reduced to ascorbate by enzymatic (Bode et al., 1993; May et al., 1998; Savini et al.,1998) and 
chemical reactions. Such reduction of dehydroascorbate to ascorbate means that dehydroascorbate snatches electrons from cytosolic components such as glutathione and other vital cellular compounds to form ascorbate, thus generating oxidative stress. The hepatocyte would not undergo oxidative stress if production rates of reducing agents such as glutathione were higher than uptake rates of oxidative agents. Therefore, high uptake rates of dehydroascorbate would be more critical than the total amount of dehydroascorbate uptake in generating oxidative stress because ingestion of large amounts of ascorbate is unrelated to oxidative stress. Ascorbate treatment decreased glutathione concentrations in liver slices and increased quantities of TBARS (lipid peroxides). These observations strongly support our hypothesis that dehydroascorbate (oxidized ascorbate) uptake generates oxidative stress.

Glutathione suppressed ascorbate-induced oxidative stress (Figure 6 ). The suppression by exogenous glutathione may not likely be caused by scavenging the oxidative potential in hepatocytes where glutathione does not easily diffuse into. Glutathione prevents the oxidation of ascorbate in medium, thus inhibiting production of dehydroascorbate. The action of glutathione is consistent with the effects of wortmannin described below. In order to explain the role of the GLUT on dehydroascorbate transport into the hepatocytes, the effects of wortmannin were tested (Figure 6, 7 and 8). Wortamannin inhibits phosphatidylinositol 3-kinase (PI3-kinase) which plays many different roles in transduction systems (Arcaro and Wymann, 1993; Clarke et al., 1994). PI3-kinase activates GLUT by translocation from its cytosolic sites to the plasma membrane (active sites). Insulin enhances glucose uptake by mobilizing GLUT from intra-cellular compartments to the plasma membrane by activating PI3-kinase (Cushman and Wardzala, 1980; Okada et al., 1994; Evans et al., 1995). Inhibition of PI3-kinase suppressed the transport capacity of GLUT (Figure 5 and 6). We, therefore, hypothesized that rates of dehydroascorbate uptake will be decreased and thus intensity of oxidative stress will be decreased in the presence of wortmannin. Our observations with wortmannin (Figure 5 and 6 ) support the hypothesis.

Also our hypothesis is supported by the observation that ascorbate consistently elevated lipid peroxide production in liver slices but that iso-ascorbate did not (Figure 4). The primary chemical structure of iso-ascorbate is the same as ascorbate and thus their red-ox potentials are equal. Therefore, the red-ox potential (reducing ability) of ascorbate is unrelated to the generation of oxidative stress. The differences in ios-ascorbate and ascorbate tertiary configurations do not confirm tertiary structure of GLUT (after oxidation of dehydroascorbate), and thus dehydro-iso-ascorbate transport into the hepatocytes is hindered. We understand that this inability of transportation by GLUT is the major reason that iso-ascorbate (via dehydroisoascorbate) cannot generate oxidative stress.

In liver homogenate dose-response curves between ascorbate concentrations and TBARS productions were a bell shape (lower panel, Figire 1 and 2). At lower concentrations ( 0.1 and $0.3 \mathrm{mM})$, ascorbate enhanced TBARS production, but was ineffective at higher concentrations ( 1 and $3 \mathrm{mM}$ ). We postulated that subcellular organelles and resealed broken down cells may pick up dehydroascorbate via a GLUT and generate oxidative stress, while the reducing property of the higher ( 1 and $3 \mathrm{mM}$ ) concentrations of ascorbate in medium overrides the oxidative stress (lower panels, Figure 1 and 2). The physical structure of subcellular organelles may be weaker than that of intact hepatocytes and cannot protect against the reducing environment in the medium.

While the results obtained in liver slices are similar to those observed during similar experiments carried out in brain cortical slices, the increases in lipid peroxidation induced by incubation with ascorbate in this experiment were less marked. For example, in the present experiment, treatment with $1 \mathrm{mM}$ ascorbate resulted in a $162 \pm 6.4 \%$ increase in TBARS levels, but exposure of brain slices to $1 \mathrm{mM}$ ascorbate resulted in a $236 \pm 20 \%$ increase in TBARS levels as compared to control (Song et al., 1999, 2001). Results may be less amplified than in those obtained in brain cortical slice studies for two reasons. While ascorbate levels increase between five and six-fold in the brain extracellular fluid during ischemia, it increases by $60 \%$ in the liver extracellular fluid during ischemia (Layton et al., 1996). The extent of dehydroascorbate transport into liver cells in order to restore the physiological concentrations of ascorbate would not significantly differ between liver and brain. Therefore comparatively smaller amounts of dehydroascorbate would be reduced back to ascorbate in liver cells, necessitating the removal of fewer electrons from the lipids that comprise the cellular membranes. In addition, the extent of peroxidation induced by incubation with ascorbate in the hepatocytes may have been lower than in cortical brain slices because the liver possesses relatively high levels of glutathione as compared to other organs. Levels of glutathione in the liver have been estimated to be $5.3 \pm 0.3 \mathrm{mM}$, while in the kidney levels are $3.00 \pm 0.18 \mathrm{mM}$ and in the colon only $0.21 \pm 0.01 \mathrm{mM}$ (Rose and Bode, 1995).

Ascorbic acid concentrations in extracellular fluid were $60 \%$ higher than controls after hypoxia (Layton et al., 1996), showing that high concentrations (4.3 \pm $0.5 \mathrm{mM}$ ) of ascorbate in the liver (Oriot et al., 1995; Rose and Bode, 1995) cannot be sustained without 
a sufficient energy supply. The released ascorbate is oxidized to dehydroascorbate, likely by molecular oxygen in plasma. This dehydroascorbate is then efficiently carried into the hepatocytes via GLUT and reduced to ascorbate. That dehydroascorbate is then recycled to ascorbate within hepatocytes, and cellular components are then oxidized during the reduction of dehydroascorbate. We suggested that dehydroascorbate could mimic the effects of ascorbate in hepatocytes, which can be considered to be a cause of liver oxidative injury during hepatic ischemia. Oxidative stress generated in liver during the post-surgical reperfusion can be attenuated by inhibiting the uptake of dehydroascorbate. Our observations hold potentially important physiological implications and the possibility that ascorbate (via dehydroascorbate) plays a pro-oxidant role in liver damage during hepatic surgery which has not previously been addressed.

In conclusion, present results support the hypothesis that the prooxidant effects of ascorbate are in fact mediated by dehydroascorbate transport. Ascorbate is easily oxidized to dehydroascorbate within the extracellular environment and then carried into cells via a GLUT. Once inside the cell, reduction back to ascorbate necessitates the removal of electrons from intracellular components. However, if these electrons are removed from vital cell components, for example the lipids that comprise cell membranes, oxidative stress may result.

\section{Acknowledgement}

These studies are partly supported by the Heart and Stroke Foundation of Ontario (NA 4474).

\section{References}

Agus D, Gambhir S, Pardridge W, Spielholz C, Baselga J, Vera J, Golde D. Vitamin C crosses the blood brain barrier in the oxidized form through the glucose transporters. J Clin Invest 1997;100:2842-8

Arcaro A, Wymann MP. Wortmannin is a potent phosphatidylinositol 3-kinase inhibitor: the role of phosphatidylinositol 3,4,5-trisphosphate in neutrophil responses. Biochem J 1993; 296:297-301

Banhegyi G, Marcolongo P, Puskas F, Fulceri R, Mandl J, Benedetti $A$. Dehydroascorbate and ascorbate transport in rat liver microsomal vesicles. J Biol Chem 1998;273:2758-62

Bode AM, Yavarow CR, Fry DA, Vargas T. Enzymatic basis for altered ascorbic acid and dehydroascorbic acid levels in diabetes. Biochem Biophys Res Commun 1993;191:1347-53

Brown S, Georgatos M, Reifel C, Song JH, Shin SH, Hong M. Recycling processes of cellular ascorbate generate oxidative stress in pancreatic tissues in in vitro system. Endocrine 2002;18:91-6
Cardoso SM, Pereira C, Oliveira CR. The protective effect of vitamin $\mathrm{E}$, idebenone and reduced glutathione on free radical mediated injury in rat brain synaptosomes. Biochem Biophys Res Commun 1998;246:703-10

Cerwenka H, Khoschsorur G, Bacher H, Werkgartner G, EIShabrawi A, Quehenberger $F$, Rabl $H$, Mischinger HJ. Normothermic liver ischemia and antioxidant treatment during hepatic resections. Free Radic Res 1999;30:463-9

Clarke JF, Young PW, Yonezawa K, Kasuga M, Holman GD. Inhibition of the translocation of GLUT1 and GLUT4 in 3T3L1 cells by the phosphatidylinositol 3-kinase inhibitor, wortmannin. Biochem J 1994;300:631-5

Cushman SW, Wardzala LJ. Potential mechanism of insulin action on glucose transport in the isolated rat adipose cell. Apparent translocation of intracellular transport systems to the plasma membrane. J Biol Chem 1980;255:4758-62

Evans JL, Honer CM, Womelsdorf BE, Kaplan EL, Bell PA. The effects of wortmannin, a potent inhibitor of phosphatidylinositol 3-kinase, on insulin-stimulated glucose transport, GLUT4 translocation, antilipolysis, and DNA synthesis. Cell Signal 1995;7:365-76

Hissin PJ, Hilf R. A fluorometric method for determination of oxidized and reduced glutathione in tissues. Anal Biochem 1976;74:214-26

Hornig D. Distribution of ascorbic acid, metabolites and analogues in man and animals. Ann N Y Acad Sci 1975;258: 103-18

Layton ME, Wood JG, Yan ZY, Forster J. Ischemia/reperfusion alters uric acid and ascorbic acid levels in liver. $J$ Surg Res 1996;64:15

Lowry $\mathrm{OH}$, Rosebrough NJ, Farr AL, Randall RJ. Protein measurements with the Folin phenol reagent. J Biol Chem 1951;193:265-75

May JM, Cobb CE, Mendiratta S, Hill KE, Burk RF. Reduction of the ascorbyl free radical to ascorbate by thioredoxin reductase. J Biol Chem 1998;273:23039-45

Miele M, Boutelle MG, Fillenz M. The physiologically induced release of ascorbate in rat brain is dependent on impulse traffic, calcium influx and glutamate uptake. Neurosci 1994; 62:87-91

Miller DM, Aust SD. Studies of ascorbatedependent, iron-catalyzed lipid peroxidation. Arch Biochem Biophys 1989;271: 113-9

Okada T, Kawano Y, Sakakibara T, Hazeki O, Ui M. Essential role of phosphatidylinositol 3-kinase in insulin-induced glucose transport and antilipolysis in rat adipocytes Studies with a selective inhibitor wortmannin. J Biol Chem 1994;269: 3568-73

Oriot D, Beharry K, Gordon JB, Aranda JV. Ascorbic acid during cerebral ischemia in newborn piglets. Acta Paediatr 1995;84:621-6

Ozaki M, Fuchinoue S, Teraoka S, Ota K. The in vivo cytoprotection of ascorbic acid against ischemia/reoxygenation injury of rat liver. Arch Biochem Biophys 1995;318: 339-445

Paolicchi A, Pezzini A, Saviozzi M, Piaggi S, Andeuccetti M, 
Shieli E, Malvaldi G, Casini A.F. Localization of a GSHDependent Dehydroascorbate Reductase in Rat Tissues and Subcellular Fractions. Arch Biochem Biophys 1995;333:489-95

Pushpendran CK, Subramanian M, Devasagayam TP, Singh BB. Study on lipid peroxidation potential in different tissues induced by ascorbate- $\mathrm{Fe}^{+}$: possible factors involved in their differential susceptibility. Mol Cell Biochem 1998;178:197-202

Ramassamy C, Girbe F, Pincemail J, Christen Y, Costentin $\mathrm{J}$. Modifications of the synaptosomal dopamine uptake and release by two systems generating free radicals: ascorbic acid/Fe2+ and L-arginine/NADPH. Ann N Y Acad Sci 1994; 738:141-152

Roginsky VA, Stegmann HB. Ascorbyl radical as natural indicator of oxidative stress: quantitative regularities. Free Radic Biol Med 1994;17:93-103

Rose RC, Bode AM. Analysis of water-soluble antioxidants by high-pressure liquid chromatography. Biochem J 1995; 306:101-5

Sakagami H, Satoh K. Modulating factors of radical intensity and cytotoxic activity of ascorbate. Anticancer Res 1997;17: 3513-20

Savini I, D'Angelo I, Annicchiarico-Petruzzelli M, Bellincampi L, Melino G, Avigliano L. Ascorbic acid recycling in Nmyc amplified human neuroblastoma cells. Anticancer Res 1998; 18:819-22

Song $\mathrm{JH}$, Harris MS, Shin SH. Effects of fetal bovine serum on ferrous ion-induced oxidative stress in pheochromocytoma (PC12) cells. Neurochem Res 2001;26:407-14
Song JH, Shin SH, Ross GM. Prooxidant effects of ascorbate in rat brain slices. J Neurosci Res 1999;58:328-36

Song $\mathrm{JH}$, Shin SH, Ross GM. Oxidative stress induced by ascorbate causes neuronal damage in an in vitro system. Brain Res 2001;895:66-72

Song JH, Shin SH, Wang W, Ross GM. Involvement of oxidative stress in ascorbate-induced proapoptotic death of PC12 cells. Exp Neurol 2001;169:425-37

Song $\mathrm{JH}$, Shin $\mathrm{SH}$, Chung IM. Effects of glutamate on dehydroascorbate uptake and Its enhanced vulnerability to the peroxidation in cerebral cortical slices. Exp Mol Med 2002; 34:419-25

Spector R, Lorenzo AV. Ascorbic acid homeostasis in the central nervous system. Am J Physiol 1973;225:757-63

Upston JM, Karjalainen A, Bygrave FL, Stocker R. Efflux of hepatic ascorbate: a potential contributor to the maintenance of plasma vitamin C. Biochem J 1999;342:49-56

Vera JC, Rivas Cl, Fischbarg J, Golde DW. Mammalian facilitative hexose transporters mediate the transport of dehydroascorbic acid. Nature 1993;364:79-82

Walker JK, Lawson BL, Jennings DB. Breath timing volume and drive to breathe in conscious rats: comparative aspects. Respir Physiol 1997;107:241-50

Welch RW, Wang Y, Crossman A Jr, Park JB, Kirk KL, Levine M. Accumulation of vitamin $C$ (ascorbate) and its oxidized metabolite dehydroascorbic acid occurs by separate mechanisms. J Biol Chem 1995;270:12584-92 